\title{
Characterization of the $\beta$-1,3-glucanase gene in peanut (Arachis hypogaea L.) by cloning and genetic transformation
}

\author{
L.X. Qiao*, X. Ding*, H.C. Wang, J.M. Sui and J.-S. Wang \\ Key Lab of Plant Biotechnology in Universities of Shandong, \\ College of Life Science, Qingdao Agriculture University, Qingdao, China \\ *These authors contributed equally to this study. \\ Corresponding author: J.-S. Wang \\ E-mail: jswang319@126.com
}

Genet. Mol. Res. 13 (1): 1893-1904 (2014)

Received January 21, 2013

Accepted August 16, 2013

Published March 17, 2014

DOI http://dx.doi.org/10.4238/2014.March.17.17

\begin{abstract}
Plant $\beta$-1,3-glucanases are commonly involved in disease resistance. This report describes the cloning and genetic transformation of a $\beta$-1,3-glucanase gene from peanut. The gene was isolated from both the genomic DNA and cDNA of peanut variety Huayu 20 by polymerase chain reaction (PCR) and reverse transcription PCR (RT-PCR), respectively. The DNA sequence contained 1471 bp including two exons and one intron, and the coding sequence contained $1047 \mathrm{bp}$ that coded for a 348-amino acid protein with a calculated molecular weight of $38.8 \mathrm{kDa}$. The sequence was registered in NCBI (GenBank accession No. JQ801335) and was designated as Ah-Glu. As determined by BLAST analysis, the Ah-Glu protein has 42-90\% homology with proteins from Oryza sativa (BAC83070.1), Zea mays (NP_001149308), Arabidopsis thaliana (NP_200470.1), Medicago sativa (ABD91577.1), and Glycine max (X̄ over-expression vector pCAMBIA1301-Glu containing Ah-Glu was constructed, confirmed by PCR and restriction enzyme digestion, and transformed into peanut variety Huayu22 by Agrobacterium EHA105-
\end{abstract}


mediated transformation. The putative transformed plants $\left(\mathrm{T}_{0}\right)$ were confirmed by PCR amplification. RT-PCR analysis and $\beta$-glucuronidase (GUS) staining showed that the transferred $A h-G l u$ was expressed as mRNA and protein. In a laboratory test, the transgenic plants were found to be more resistant to the fungal pathogen Cercospora personata than the non-transgenic plants were.

Key words: Peanut; Arachis hypogaea L.; $\beta$-1,3-glucanase gene; Vector construction; Genetic transformation; Disease resistance

\section{INTRODUCTION}

Plants use a variety of mechanisms to defend against pathogens (Boller, 1985), and one such mechanism involves $\beta$-1,3-glucanase. As a pathogenesis-related protein, $\beta$-1,3-glucanase, acting alone and particularly in combination with chitinase, can protect plants against fungal infection in two ways. The first is by directly weakening and decomposing fungal cell walls, the most abundant components of which are glucan and chitin (Bartnicki-Garcia, 1968). $\beta$-1,3-glucanase can also act indirectly, by releasing elicitors through limited hydrolysis of the fungal cell wall that can then induce defense reactions (Lawrence et al., 2000). $\beta$-1,3-glucanase has been shown to inhibit the growth of many fungal pathogens and has been closely associated with disease resistance (Momein, 2008). When grapevines were inoculated with Botrytis cinerea, $\beta$-1,3-glucanase mRNAs and corresponding proteins were subsequently detected in leaves 3-7 days later (Renault et al., 2000). Inoculation of wheat with Bipolaris sorokiniana resulted in the induction of a $\beta$-1,3-glucanase II gene; induction was greater in the resistant genotype, Chiriya-3, than in the highly susceptible genotype, Agra Local, indicating that $\beta-1,3$-glucanase production may be involved in resistance to the pathogen (Aggarwal et al., 2011). The activities of $\beta$-1,3-glucanase were found to be similar in the uninfected peanut seed of all genotypes, but were significantly higher in resistant genotypes than in susceptible genotypes after inoculation with Aspergillus flavus (Liang et al., 2005). Higher $\beta$-1,3-glucanase activity in maize kernels of a resistant genotype, relative to the susceptible genotype, was also correlated with lower A. flavus infection (Lozovaya et al., 1998).

Pathogen-induced $\beta$-1,3-glucanase genes have been cloned in wheat (Li et al., 2001), rice (Yamaguchi et al., 2002), Arabidopsis (Dong et al., 1991), soybean (Takeuchi et al., 1990), and alfalfa (Masoud et al., 1996). In plants, $\beta$-1,3-glucanases are encoded by a small gene family, and the products of these genes consist of seven isoenzymes, designated as GI to GVII ( $\mathrm{Li}$ et al., 1996). There is increasing evidence that GII is particularly important in the plant response to pathogen attack (Roulin et al., 1997). The exogenous $\beta$-1,3-glucanase gene from bacteria and plants could be transferred to and expressed in transgenic plants such as potato (Martin, 1994), tobacco (Darbinian et al., 1996; Herbers et al., 1996), and barley (Jensen et al., 1996). The $\beta$-1,3-glucanase gene from soybean enhanced resistance to Phytophthora parasitica and Alternaria alternata in transgenic tobacco (Yoshikawa and Sugimoto, 1993; Lusso and Kuc, 1996), and to B. cinerea in transgenic kiwifruit (Nakamura et al., 1999). Transgenic rice plants that expressed the $\beta-1,3(1,4)$-glucanase gene Gns 1 had less severe symptoms than non-transgenic plants when infected with the blast fungus Magnaporthe grisea (Nishizawa et al., 2003). 
The current study reports on a previously undescribed $\beta$-1,3-glucanase gene in peanut (Arachis hypogaea L.). Peanut is the third most important oilseed crop in the world. It is grown extensively throughout the semi-arid tropics of Asia, Africa, and Latin America, and has a global production of 35.52 million tons across 23.5 million ha (FAO, 2009). Cultivated peanut is susceptible to many fungal pathogens, including Cercospora arachidicola, Cercospora personata, and A. flavus. Because infection by this fungus could reduce yield and even aflatoxin contamination by A. flavus, enhancing the resistance of cultivated peanut to fungal pathogens is important. The cloning and overexpression of resistance genes can be an effective way to increase disease resistance in plants. In the current study, we isolated a $\beta$-1,3-glucanase gene from peanut leaves and transferred the gene to peanut, aiming to increase disease resistance in transgenic peanut by overexpression of the gene.

\section{MATERIAL AND METHODS}

\section{Plant materials, strains, and plasmids}

The peanut varieties Huayu20 and Huayu22, plasmid pCAMBIA1301, Escherichia coli DH-5 $\alpha$, and Agrobacterium EHA105 were maintained in the genetics laboratory of Qingdao Agricultural University. The fungal pathogen C. personata was provided by Dr. Yucheng Chi of the Shandong Peanut Research Institute. Plasmids and restriction enzymes were obtained from TaKaRa Biotechnology Co., Ltd. (Dalian, China).

\section{Plant growth and induction treatments}

Seeds of peanut variety Huyu20 were surface sterilized in 1\% sodium hypochlorite for $15 \mathrm{~min}$, germinated on Murashige and Skoog medium, and grown in a chamber at $24^{\circ} \pm$ $1{ }^{\circ} \mathrm{C}, 3000 \mathrm{~lx}$, and $13 \mathrm{~h}$ light per day. When seedlings were 14 days old, they were sprayed with $1.5 \mathrm{mM}$ salicylic acid (SA), a signaling molecule capable of inducing the disease resistance response in plants. DNA and RNA were extracted from seedlings $48 \mathrm{~h}$ after being sprayed with $\mathrm{SA}$, as described in the next section.

\section{DNA extraction, RNA extraction, and cDNA synthesis}

Genomic DNA was isolated from the green leaves of 16-day-old seedlings using the cetyltrimethylammonium bromide (CTAB) method (Yin et al., 2011). Total RNA was isolated from approximately $300 \mathrm{mg}$ frozen green leaves using the Trizol ${ }^{\mathrm{TM}}$ reagent (TaKaRa), according to manufacturer recommendations. The first-strand cDNA was synthesized using Moloney murine leukemia virus (MMLV) reverse transcriptase (TaKaRa) with the Oligo(dT)18 primer following manufacturer instructions.

\section{Molecular cloning and sequence analysis}

Gene-specific primers (Table 1) were designed and synthesized according to the predicted sequence, which was obtained by TBLASTN in the National Center for Biotechnology Information (NCBI) using the conservative amino acid sequence of $\beta$-1,3-glucanase from Arabidopsis thaliana (GenBank No. AAA32864.1). 
Table 1. PCR primer sequences used for $\beta$-1,3-glucanase gene cloning and molecular amplification of transgenic peanut plants.

\begin{tabular}{ll}
\hline Primer & Sequence (5' to 3') \\
\hline Ah-Glu $(\mathrm{F})$ & AGCTTCAGCTTCACCTCTCG \\
Ah-Glu $(\mathrm{R})$ & CAACAGCACCTCTTCAAGTG \\
Ah-Actin $(\mathrm{F})$ & GTGGCCGTACAACTGGTATTGT \\
Ah-Actin $(\mathrm{R})$ & ATGGATGGCTGGAAGAGACT \\
Gus $(\mathrm{F})$ & CACACCGATACCATCAGAGAT \\
Gus $(\mathrm{R})$ & TCACCGAAGGGCATGCCAGTC \\
\hline
\end{tabular}

Polymerase chain reaction (PCR) and reverse transcription (RT)-PCR amplification were conducted using the genomic DNA and cDNA of peanut variety Huyu20 as the template, respectively. For both DNA and cDNA, the PCR amplification conditions were: $94^{\circ} \mathrm{C}$ denaturation for $5 \mathrm{~min}$; followed by 35 cycles of $94^{\circ} \mathrm{C}$ for $1 \mathrm{~min}, 58^{\circ} \mathrm{C}$ for $1 \mathrm{~min}$, and $72^{\circ} \mathrm{C}$ for $1 \mathrm{~min}$; and $72^{\circ} \mathrm{C}$ elongation for $10 \mathrm{~min}$. The amplification products were cloned into the pMD-18T vector for sequencing.

The conserved domains in the open reading frames were identified using the NCBI Conserved Domain Database (NCBI-CDD). Protein molecular mass was predicted and was calculated using the DNAMAN software. Multiple sequence alignments of deduced amino acids and phylogenetic analysis were carried out in the GenBank website using the BLAST program. N-terminal signal peptides were predicted using the online PSORT version 6.4 software for plants. Cleavage of the signal peptide was predicted based on SignalP 3.0. The putative protein structure was analyzed using the NCBI Protein Homology Modeling program.

\section{Construction of plant expression vector and genetic transformation}

A new recombinant plasmid was obtained by recovery and ligation of the 20- and $1.1-\mathrm{kb}$ fragments that were produced when the plasmids pCAMBIA1301 and pMD18T-Glu were digested by restriction enzymes $X b a \mathrm{I}$ and $P s t \mathrm{I}$, respectively. The recombinant plasmid contained the $\beta-1,3$-glucanase gene from peanut, and it was named pCAMBIA1301-Glu.

The recombinant plasmid pCAMBIA1301-Glu was then introduced into peanut cultivar Huayu22 using an Agrobacterium-mediated method, as reported previously (Zhang et al., 2008). Embryonic leaflets from the seeds of peanut cultivar Huayu22 were used as explants, which were infected with Agrobacterium EHA105 carrying the recombinant plasmid pCAMBIA1301-Glu. After 3 days of co-cultivation, the transformed explants were cultured in somatic embryo induction medium for 4 weeks, and were then transferred to somatic embryo germination medium for 4 months at $24^{\circ} \pm 1^{\circ} \mathrm{C}$ under a 13-h light/11-h dark cycle. The explants were selected using $15 \mathrm{mg} / \mathrm{L}$ hygromycin as the selection marker.

\section{PCR, RT-PCR identification, and $\beta$-glucuronidase (GUS) histochemical analysis}

PCR was performed using genomic DNA from leaves of transgenic and non-transgenic plants and GUS primers (Table 1). The PCR conditions were $94^{\circ} \mathrm{C}$ for $5 \mathrm{~min}$; followed by $35 \mathrm{cy}-$ cles of $94^{\circ} \mathrm{C}$ for $45 \mathrm{~s}, 56^{\circ} \mathrm{C}$ for $45 \mathrm{~s}$, and $72^{\circ} \mathrm{C}$ for $45 \mathrm{~s}$; and a final extension at $72^{\circ} \mathrm{C}$ for $10 \mathrm{~min}$.

RT-PCR was performed using total RNA from leaves of transgenic and non-transgenic plants and $A h$-Glu primers (Table 1). As an internal control, the Ah-Actin gene was also amplified 
using specific primers (Table 1). The PCR conditions were $94^{\circ} \mathrm{C}$ for $5 \mathrm{~min}$; followed by $35 \mathrm{cy}-$ cles of $94^{\circ} \mathrm{C}$ for $45 \mathrm{~s}, 54^{\circ} \mathrm{C}$ for $45 \mathrm{~s}$, and $72^{\circ} \mathrm{C}$ for $45 \mathrm{~s}$; and a final extension at $72^{\circ} \mathrm{C}$ for $10 \mathrm{~min}$. The amplified products from both PCR and RT-PCR were analyzed on 1\% (w/v) agarose gels.

Four-month-old detached leaves from transgenic plants, which were confirmed positive by PCR and RT-PCR, and control plants were used for GUS staining using X-Gluc as a substrate. After staining, the leaves were incubated at $37^{\circ} \mathrm{C}$ for $3-12 \mathrm{~h}$. They were then subjected to 2-3 washes with 70\% alcohol for discoloration until the control leaves became yellow or white (Zhu et al., 2009).

\section{Disease-resistance assays}

The disease resistance of the transgenic plants was evaluated as reported previously (Shokes et al., 1987). Briefly, 4-month-old detached leaves of transgenic plants were inoculated with one $6 \mathrm{~mm}$-diameter plug of PDA colonized with $C$. personata, which was fixed in both sides of the leaves. The leaves of non-transgenic plants were also inoculated as controls using the same methods. These leaves were then placed in flasks containing sterilized damp sandy soil to maintain enough humidity at $26^{\circ} \mathrm{C}$. After 2 weeks, leaves were visually evaluated for disease symptoms.

\section{RESULTS}

\section{Cloning and sequence analysis of the $\beta$-1,3-glucanase gene from peanut}

When cDNA from plants treated with SA was used as templates, a 1.1-kbp fragment was obtained by RT-PCR. No corresponding fragment was obtained when cDNA from plants not treated with SA was used as the templates (Figure 1). When DNA from plants was used as templates, a 1.5-kbp fragment was obtained by PCR (Figure 1). The two amplified fragments were cloned and then sequenced by the Sangon Company (Shanghai, China). Comparison of DNA and cDNA sequences showed that the DNA sequence contained $1471 \mathrm{bp}$, including two exons and one intron, and the coding sequence contained 1047 bp that coded for 348 amino acids. The gene was named $A h-G l u$. The sequence of $A h-G l u$ has been registered in GenBank with the accession No. JQ801335.

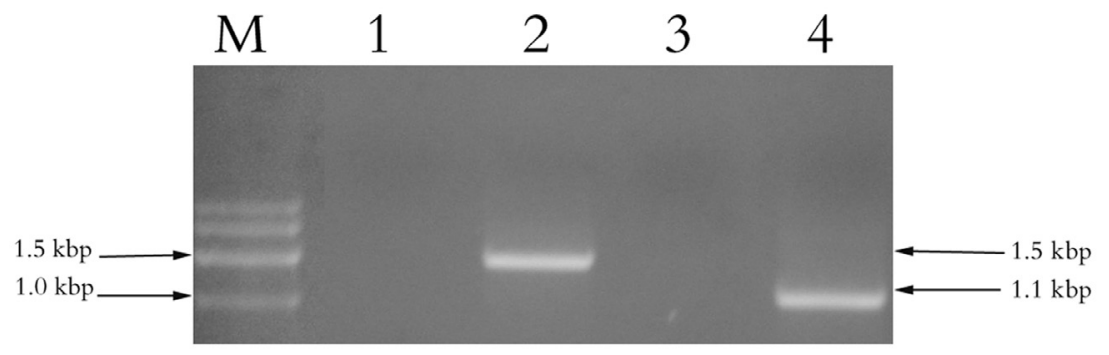

Figure 1. Products produced by PCR and RT-PCR amplification based on DNA and cDNA templates using primers Ah-Glu (F) and Ah-Glu (R). Lane $M=$ marker G; lane $1=$ control without DNA; lane 2 = product from DNA amplification; lane $3=$ product from cDNA amplification without induction by salicylic acid; lane 4 = product from cDNA amplification with induction by salicylic acid. 
Analysis by NCBI-CDD revealed that the Ah-Glu protein contained a typical glycosyl hydrolase family 17 (GH17) domain with the common amino acid sequence of (LIVM)-X(LIVMFVW)3-(STAG)-E-(ST)-G-W-P-(ST)-X-G. The GH17 domain of the Ah-Glu protein was located between amino acid 260 and 274 with sequence IKIMVTETGWPSKG (Figure 2A). Multiple sequence alignment showed that the Ah-Glu protein had high homology with $\beta$-1,3-glucanase 13 from Glycine max (XP_003530515.1), Vitis vinifera (XP_002283473.1), and with the glycosyl hydrolase family 17 protein of $A$. thaliana (XP_002864470.1); the similarity coefficients were 90,84 , and $72 \%$, respectively (Figure $2 B$ ).

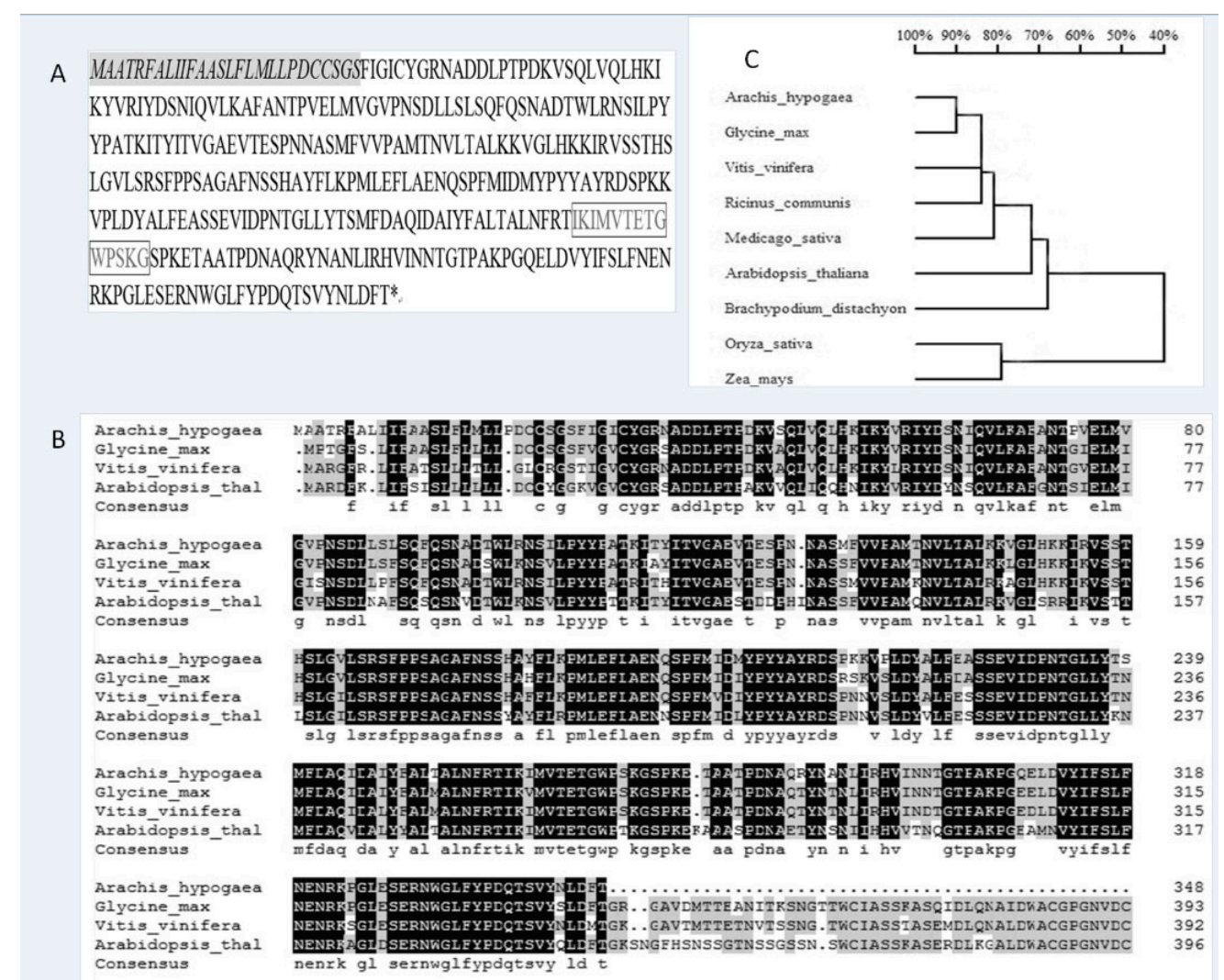

Figure 2. Amino acid sequence of the $\beta$-1,3-glucanase protein from peanut and sequence alignment in higher plants. A. Amino acid sequence of the $\beta-1,3$-glucanase protein from peanut. The shaded sequence is signaling peptide, the sequences in rectangle are glycosyl hydrolase family 17 domain. B. Amino acid alignment of $\beta$-1,3-glucanase proteins in higher plants. Dark shading with white letters reveal 100\% sequence conservation. Database accession Nos. are JQ801335 from Arachis hypogaea, XP_003530515.1 from Glycine max, XP_002283473.1 from Vitis vinifera, XP_002864470.1 from glycosyl hydrolase family 17 protein of Arabidopsis thaliana. C. Phylogenetic tree of the $\beta-1,3$-glucanase protein in higher plants. The species names are listed on the left side, and the homologies are listed above. Database accession numbers are JQ801335 from Arachis hypogaea, BAC83070.1 from Oryza sativa, NP_001149308.1 from Zea mays, ABD91577.1 from Medicago sativa, XP_002514201.1 Ricinus communis, and XP_003530515.1 from Glycine max.

A phylogenetic tree was generated by BLAST analysis in GenBank based on the amino acid sequences of $\beta$-1,3-glucanase from different plants (Figure $2 \mathrm{C}$ ). The results showed 
that the Ah-Glu protein was more closely related to the $\beta$-1,3-glucanase from G. max, Medicago sativa, and Ricinus communis than to those from Oryza sativa and Zea mays. The similarity coefficients between the peanut $\beta$-1,3-glucanase with those from O. sativa (BAC83070.1), $Z$. mays (NP_001149308.1), M. sativa (ABD91577.1), R. communis (XP_002514201.1), and G. $\max \left(X P \_003530515.1\right.$ ) were 42, 44, 80, 84, and 90\%, respectively.

The Ah-Glu protein contains 348 amino acids with a theoretical molecular mass of 38.8 $\mathrm{kDa}$ and a calculated isoelectric point of 6.85 , which indicates that the protein is acidic. Analysis of the amino acid sequence by SignalP 3.0 predicted the existence of a signaling peptide, which is located at the $N$-terminus of the protein from position 1 to 28 . Two possible cleavage sites within the signal sequence lie between amino acid position 26 and 27 (Figure 2A).

\section{Construction of a plant expression vector and genetic transformation}

As shown in Figure 3A, the recombinant plasmid pCAMBIA1301-Glu was obtained by inserting $A h$-Glu into the site of the plasmid pCAMBIA1301 between the actin promoter and the OCS terminator sequence. When the recombinant plasmid was subjected to PCR amplification and the products were digested with restriction enzymes $X b a \mathrm{I}$ and $P s t \mathrm{I}$, a $1.1-\mathrm{kb}$ fragment was obtained (Figure 3B), indicating that $A h$-Glu had been correctly inserted into the plasmid.

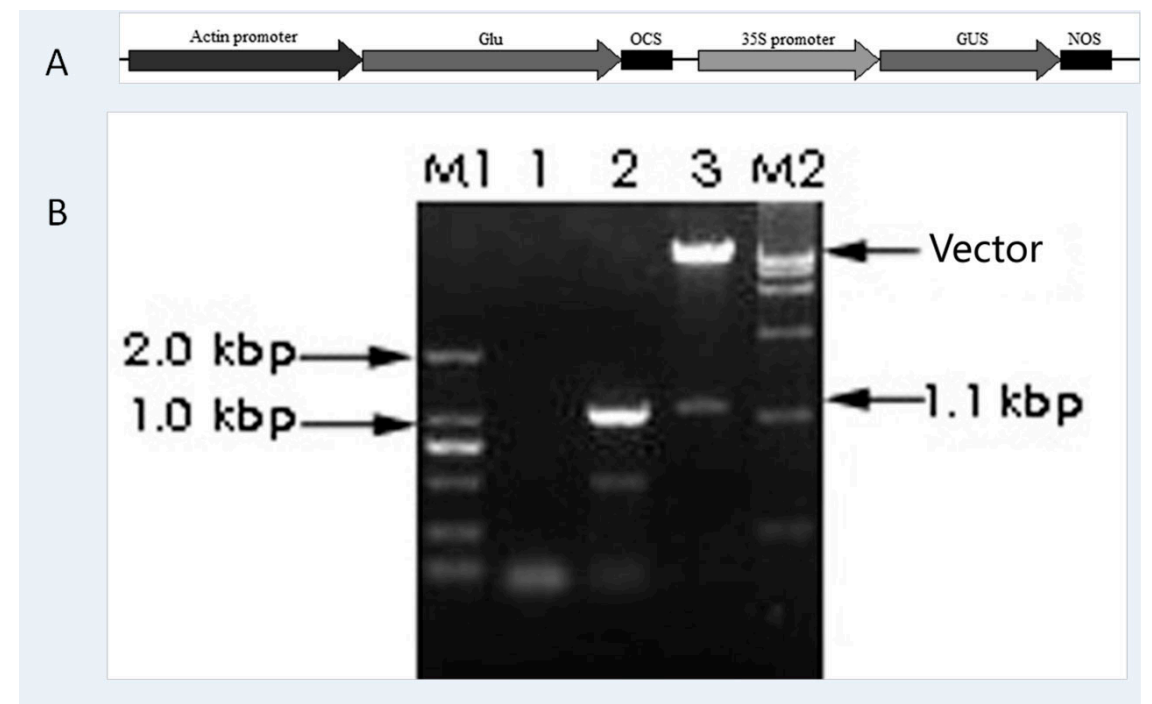

Figure 3. Schematic representation and confirmation on the recombinant plasmid pCAMBIA1301-Glu. A. Schematic representation of pCAMBIA1301-Glu. Glu = $\beta$-1,3-glucanase from Arachis hypogaea; OCS = octopine synthase terminator; GUS = beta-glucuronidase as a reporter gene; NOS = nopaline synthase terminator. $\mathbf{B}$. Confirmation of pCAMBIA1301-Glu by PCR amplification and restriction enzyme analysis. Lane M1 = DL 2000 marker; lane $1=$ PCR control without DNA; lane 2 = PCR amplification product by Ah-Glu (F) and Ah-Glu (R); lane 3 = recombinant plasmid digested with $X b a \mathrm{I}$ and PstI; lane M2 = DL15000 marker.

Somatic embryos were obtained after transformed embryonic leaflets were cultured in somatic embryo induction medium for 4 weeks (Figure 4a). Germinating seedlings and regenerated plants were obtained after somatic embryos were cultured in somatic embryo germination medium for 4 and 12 weeks, respectively (Figure $4 \mathrm{~b}$ and c). 


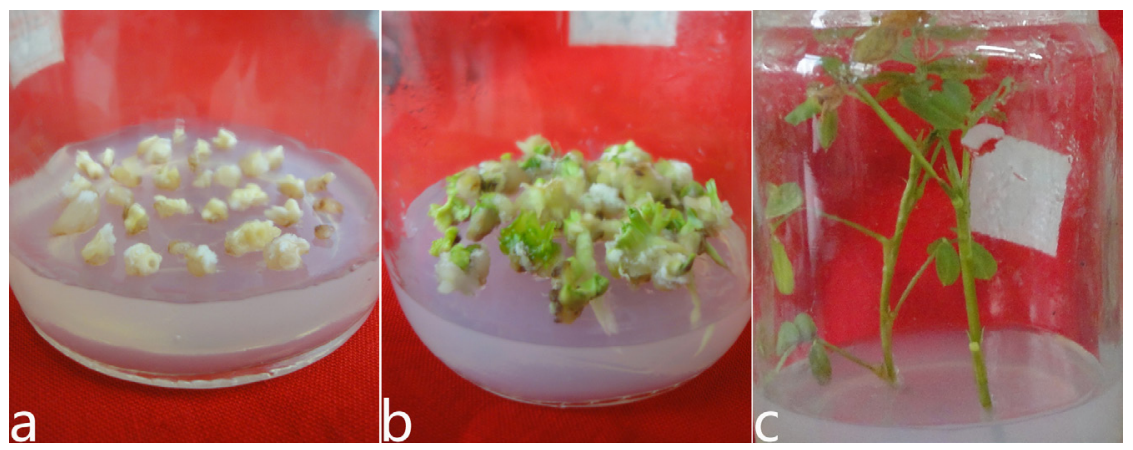

Figure 4. Plant regeneration from transformed explants of peanut embryonic leaflets. a. Somatic embryo from transformed explants cultured in somatic embryo induction medium for 4 weeks; b. young seedlings from somatic embryo cultured in somatic embryo germination medium for 4 weeks; c. regenerated plants from young seedlings cultured in somatic embryo germination medium for 8 weeks.

\section{PCR, RT-PCR identification, and GUS histochemical analysis}

The corresponding GUS target fragments (410 bp) were obtained in some regeneration plants by PCR amplification (Figure $5 \mathrm{~A}$ ), which showed that the plasmid had been transferred to these plants. The corresponding $A h-G l u$ target fragments $(1.1 \mathrm{~kb})$ were obtained from some transgenic plants by RT-PCR amplification, while no corresponding target fragments were obtained from the non-transgenic plants (Figure 5B), which showed that the transferred gene had been expressed in mRNA. The peanut actin fragments (Ah-Actin) were obtained from both transgenic and control plants (Figure 5B). Detached leaves from transgenic plants were stained blue while those from control plants were not (Figure 6), indicating that the GUS gene had been expressed in the mRNA of transgenic plants.

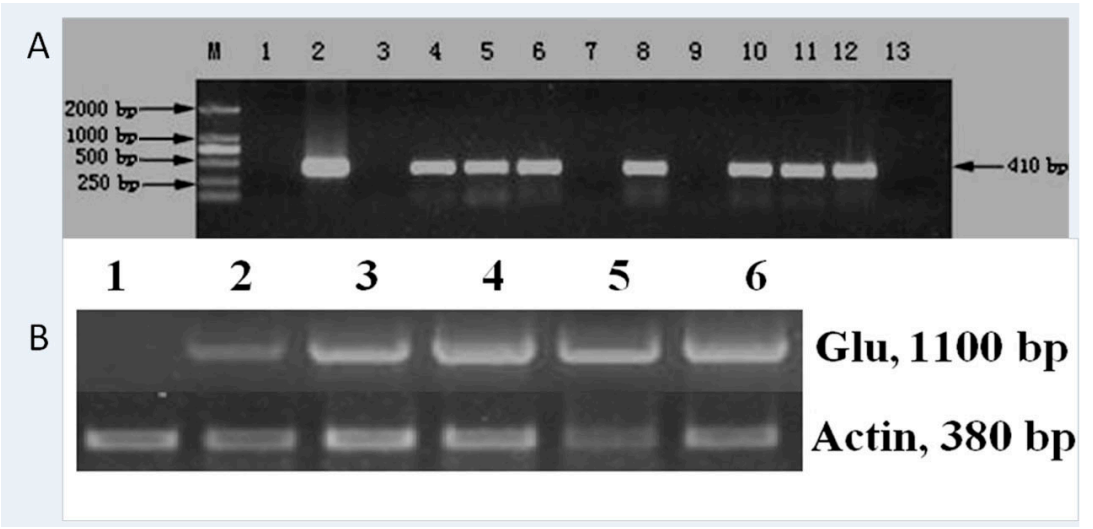

Figure 5. Confirmation on transgenic plants in DNA and mRNA using PCR and RT-PCR amplification. A. PCR amplification of the regeneration plants by $A h-G l u(\mathrm{~F})$ and $A h-G l u(\mathrm{R})$. Lane $1=$ control without DNA; lane 2 = products from recombinant plasmid pCAMBIA1301-Glu; lane 3-13= products from regeneration plants. B. Expression analysis in mRNA using RT-PCR amplification. Upper panel is the products amplified by $A h-G l u(\mathrm{~F})$ and $A h-G l u(\mathrm{R})$; lower panel is the products amplified by Ah-Actin (F) and Ah-Actin (R). Lane 1 = products from non-transgenic plants; lanes $2-6=$ products from transgenic plants. 


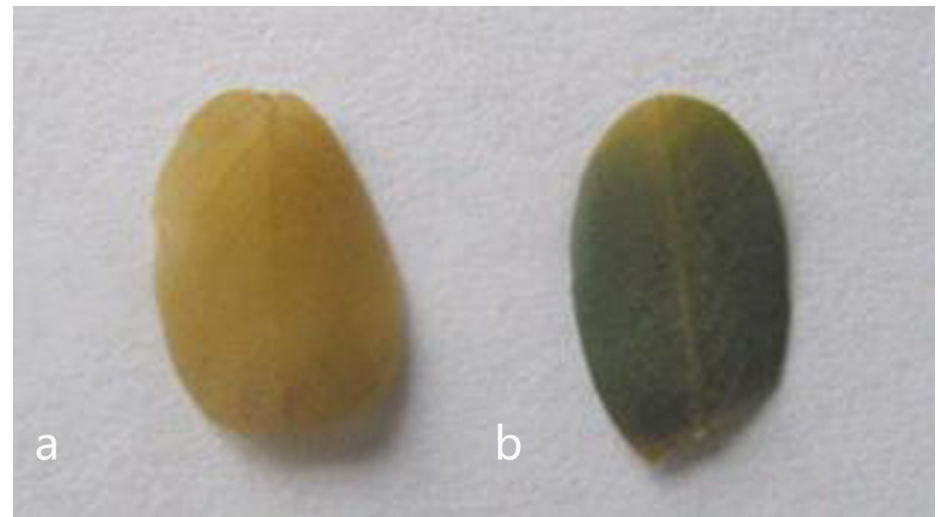

Figure 6. Expression confirmation on the leaves of transgenic plants by GUS staining. a. Yellow leaves from nontransgenic plants; b. blue leaves from transgenic plants.

\section{Disease-resistance assays}

Detached leaves became brown 2 weeks after they were inoculated with C. personata in the laboratory assay. Browning of the leaves was more severe in non-transgenic plants than in transgenic plants. As shown in Figure 7, leaves from non-transgenic plants appeared to be severely necrotic, whereas leaves from transgenic plants remained green.

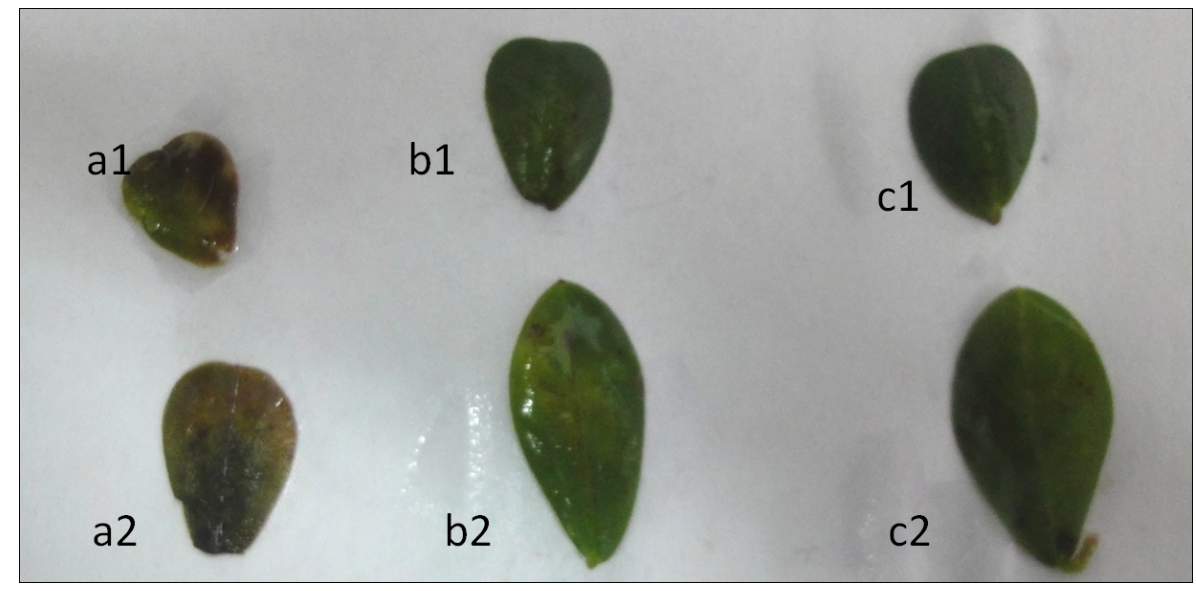

Figure 7. Development of disease symptoms on detached leaves 2 weeks after inoculated with Cercospora personata. a1 and $\mathrm{a} 2=$ severe necrosis and browning leaves from non-transgenic plants; $\mathrm{b} 1$ and $\mathrm{b} 2$, $\mathrm{c} 1$ and $\mathrm{c} 2=$ leaves which could keep green and were less necrosis and browning from transgenic plants.

\section{DISCUSSION}

$\beta$-1,3-glucanase is a well-known pathogenesis-related protein that is constitutively expressed at low levels in plants and can be dramatically induced when plants are infected by 
fungal, bacterial, or viral pathogens (Lan et al., 2000; Xing and Wang, 2002). In this study, the $\beta$-1,3-glucanase gene $(1.1 \mathrm{kbp})$ from peanut was obtained by RT-PCR with cDNA template after induction by SA, and no corresponding fragment was obtained in the absence of SA induction. This indicates that constitutive gene expression in peanut is too low to be detected unless the plant is treated with an elicitor or is challenged by a pathogen. A $1.5-\mathrm{kbp}$ fragment was obtained by PCR when DNA was used as the template. Comparison of DNA and cDNA sequences showed that the gene contains two exons and one intron, and encodes a protein with 348 amino acids with a molecular weight of $38.81 \mathrm{kDa}$ and an isoelectric point of 6.85 .

Systemic acquired resistance (SAR) and induced systemic resistance (ISR) are two forms of induced resistance, and SA is considered as the key regulator of these two types of induced defense responses in plants (Durrant and Dong, 2004). In the current study, SA treatment resulted in an accumulation of $A h-G l u$ transcripts, suggesting that $A h-G l u$ might be involved in defense response in either SAR or ISR.

Previous reports have indicated that many $\beta$-1,3-glucanase genes contain a single intron that is approximately $250-1000$ bp long (von-Heijne, 1983), and that the first exon of $\beta$-1,3-glucanase genes usually encodes the major portion of the signal peptide (von-Heijne, 1983). The lengths of the introns from bamboo, peaches, and curled-leaved tobacco were found to be 520, 256, and $975 \mathrm{bp}$, respectively (Gheysen et al., 1990; Thimmapuram et al., 2001; Ko et al., 2003). Ah-Glu contains a 434-bp intron, which is in accordance with the "GT...AG" intron splice law, and its first exon encodes 21 of the 28 amino acids of a putative signal peptide. According to the predicted isoelectric point and signal peptide, the Ah-Glu protein might be an acid that is secreted into the extracellular space.

Sequence alignment showed that the Ah-Glu protein might belong to the $\beta-1,3$-glucanase 13 and glycosyl hydrolase family 17; the similarity coefficient was $78 \%$ for the former and was $90 \%$ for the latter. At the protein level, the sequence identity of the Ah-Glu protein with those from other plants was $42-90 \%$. The identity was high with dicots such as soybean $(90 \%)$ and grape (84\%), and was low with the monocots rice (42\%) and corn $(44 \%)$. The phylogenetic tree indicated that the proteins formed two major groups, i.e., monocots and dicots, with the exception of Brachypodium distachyon; although $B$. distachyon is a monocot, it clustered with the dicots. This suggests that phylogenetic trees constructed with a specific marker may not be consistent with traditional classifications.

In an effort to enhance disease resistance, the plant expression vector was constructed and $A h-G l u$ was introduced into peanut variety Huayu22. The transferred $A h-G l u$ was expressed as mRNA, and disease resistance was enhanced in transgenic plants. Although the defensive role of $A h$-Glu against fungal pathogens is far from being fully understood, our results indicate that $\beta-1,3$-glucanase is involved in the resistance response of peanut to C. personata. Determining how $\beta-1,3$-glucanase is involved in the response of peanut to fungal pathogens will require additional research.

\section{ACKNOWLEDGMENTS}

Research supported by the National Natural Science Foundation of China (\#31101178), the Shandong Provincial Research Foundation for Young Researchers (\#BS2009NY028), and International Cooperation Program of Shandong Provincial Education Department, China. We thank Dr. Yucheng Chi for providing Cercospora personata. 


\section{REFERENCES}

Aggarwal R, Purwar S, Kharbikar LL and Sangeeta G (2011). Induction of a wheat $\beta$-1,3-glucanase gene during the defense response to Bipolaris sorokiniana. Acta Phytopathol. Entomol. Hung. 46: 39-47.

Bartnicki-Garcia S (1968). Cell wall chemistry, morphogenesis, and taxonomy of fungi. Annu. Rev. Microbiol. 22: 87-108.

Boller T (1985). Induction of Hydrolases as Defense Reaction Against Pathogens. In: Cellular and Molecular Biology of Plant Stress (Key JL and Kosuge T, eds.). Alan R. Liss, Inc., NewYork, 247-262.

Darbinian NS, Popov I, Mochul'skii AV, Volkova LV, et al. (1996). Construction and analysis of transgenic plants of Nicotiana tabacum L. expressing a bacterial gene for $\beta$-1,3-glucanase. I. Construction of vector plasmids for transfer into plants and expression of a modified gene for $\beta-1,3$-glucanase from Clostridium thermocellum in tobacco protoplasts. Genetika 32: 197-203.

Dong X, Mindrinos M, Davis KR and Ausubel FM (1991). Induction of Arabidopsis defense genes by virulent and avirulent Pseudomonas syringae strains and by a cloned avirulence gene. Plant Cell 3: 61-72.

Durrant WE and Dong X (2004). Systemic acquired resistance. Annu. Rev. Phytopathol. 42: 185-209.

FAO (2009). FAO Statistical Database. Available at [http://faostat.fao.org/]. Accessed May 3, 2011.

Gheysen G, Inze D, Soetaert P, Van Montagu M, et al. (1990). Sequence of a Nicotiana plumbaginifolia $\beta(1,3)$-glucanase gene encoding a vacuolar isoform. Nucleic Acids Res. 18: 66-85.

Herbers K, Flint HJ and Sonnewald U (1996). Apoplastic expression of the xylanase and $\beta(1-3,1-4)$ glucanase domains of the xynD gene from Ruminococcus flavefaciens leads to functional polypeptides in transgenic tobacco plants. Mol. Breed.: New Strateg. Plant Improv. 2: 81-87.

Jensen LG, Olsen O, Kops O, Wolf N, et al. (1996). Transgenic barley expressing a protein-engineered, thermostable (1,3-1,4)-ß-glucanase during germination. Proc. Natl. Acad. Sci. U. S. A. 93: 3487-3491.

Ko TS, Lee S, Schaefer SC and Korban SS (2003). Characterization of a tissue-specific and developmentally regulated small $\beta$-1,3-glucanase gene family in Prunus persica. Plant Physiol. Biochem. 41: 955-963.

Lan HY, Tian YC, Wang CH, Liu GZ, et al. (2000). Studies of transgenic tobacco plants expressing $\beta-1,3$-glucanase and chitinase genes and their potential for fungal resistance. Yi Chuan Xue Bao 27: 70-77.

Lawrence CB, Singh NP, Qiu J, Gardner RG, et al. (2000). Constitutive hydrolytic enzymes are associated with polygenic resistance of tomato to Alternaria solani and may function as an elicitor release mechanism. Physiol. Mol. Plant Pathol. 57: 211-220.

Li CD, Langridge P, Lance RCM, Xu P, et al. (1996). Seven members of the (1-3)- $\beta$-glucanase gene family in barley (Hordeum vulgare) are clustered on the long arm of chromosome 3 (3HL). Theor. Appl. Genet. 92: 791-796.

Li WL, Faris JD, Muthukrishnan S, Liu DJ, et al. (2001). Isolation and characterization of novel cDNA clones of acidic chitinases and $\beta-1,3$-glucanases from wheat spikes infected by Fusarium graminearum. Theor. Appl. Genet. 102: 353-362.

Liang XQ, Holbrook CC, Lynch RE and Guo BZ (2005). $\beta$-1,3-Glucanase activity in peanut seed (Arachis hypogaea) is induced by inoculation with Aspergillus flavus and copurifies with a conglutin-like protein. Phytopathology 95: 506-511.

Lozovaya VV, Waranyuwat A and Widholm JM (1998). $\beta-1,3-$-Glucanase and resistance to Aspergillus flavus infection in maize. Crop Sci. 38: 1255-1260.

Lusso M and Kuc J (1996). The effect of sense and anti-sense expression of the PR-N gene for $\beta$-1,3-glucanase on disease resistance of tobacco to fungi and viruses. Physiol. Mol. Plant P. 49: 267-283.

Martin RR (1994). Genetic engineering of potatoes. Am. J. Potato Res. 71: 347-358.

Masoud SA, Zhu Q, Lamb C and Dixon RA (1996). Constitutive expression of an inducible $\beta$-1,3-glucanase in alfalfa reduces disease severity caused by the oomycete pathogen Phytophthora megasperma f. sp. medicaginis, but does not reduce disease severity of chitin-containing fungi. Transgenic Res. 5: 313-323.

Momein HA El-Katatny (2008). The activity of $\beta$-1,3-glucanase from Trichoderma harzianum in native form and after immobilization on calcium alginate. Arch. Phyto. Plant Prot. 41: 175-186.

Nakamura Y, Sawada H, Kobayashi S, Nakajima I, et al. (1999). Expression of soybean $\beta-1,3$-endoglucanase cDNA and effect on disease tolerance in kiwifruit plants. Plant Cell Rep. 18: 527-532.

Nishizawa Y, Saruta M, Nakazono K, Nishio Z, et al. (2003). Characterization of transgenic rice plants over-expressing the stress-inducible $\beta$-glucanase gene Gns 1. Plant Mol. Biol. 51: 143-152.

Renault AS, Deloire A, Letinois I, Kraeva E, et al. (2000). $\beta-1,3-$ Glucanase gene expression in grapevine leaves as a response to infection with Botrytis cinerea. Am. J. Enol. Vitic. 51: 81-87.

Roulin S, Xu P, Brown AHD and Fincher GB (1997). Expression of specific (1-3)- $\beta$-glucanase gene in leaves of nearisogenic resistant and susceptible barley lines infected with the leaf scald fungus (Rhynchosporium secalis). Physiol. Mol. Plant Pathol. 50: 245-261. 
Shokes FM, Berger RD, Smith DH and Rasp JM (1987). Reliability of disease assessment procedures: A case study with late leaf spot of peanut. Oleagineux 42: 245-251.

Takeuchi Y, Yoshikawa M, Takeba G, Tanaka K, et al. (1990). Molecular cloning and ethylene induction of mrna encoding a phytoalexin elicitor-releasing factor, $\beta-1,3$-endoglucanase, in soybean. Plant Physiol. 93: 673-682.

Thimmapuram J, Ko TS and Korban SS (2001). Characterization and expression of $\beta$-1,3-glucanase genes in peach. Mol. Genet. Genomics 265: 469-479.

von-Heijne G (1983). Patterns of amino acids near signal-sequence cleavage sites. Eur. J. Biochem. 133: 17-21.

Xing QH and Wang B (2002). Advances on the plant disease resistant $\beta$-glucanase gene. Yi Chuan 24: 715-720.

Yamaguchi T, Nakayama K, Hayashi T, Tanaka Y, et al. (2002). Molecular cloning and characterization of a novel $\beta-1,3-$ glucanase gene from rice. Biosci. Biotechnol. Biochem. 66: 1403-1406.

Yin D, Liu H, Zhang X and Cui D (2011). A protocol for extraction of high-quality RNA and DNA from peanut plant tissues. Mol. Biotechnol. 49: 187-191.

Yoshikawa M and Sugimoto K (1993). A specific binding site on soybean membrances for a phtyoalexin elicitor released from fungal cell wall by $\beta$-1,3-endoglucanase. Plant Cell Physiol. 34: 1229-1237.

Zhang LF, Wang B, Gai WL, Wang XJ, et al. (2008). Studies on transformation of peanut with CH5B gene mediated by Agrobacterium tumefaciens. J. Qingdao Agri. Univ. 25: 84-87.

Zhu Y, Wang Z, Jing Y, Wang L, et al. (2009). Ectopic over-expression of BhHsf1, a heat shock factor from the resurrection plant Boea hygrometrica, leads to increased thermotolerance and retarded growth in transgenic Arabidopsis and tobacco. Plant Mol. Biol. 71: 451-467. 